\title{
'Hodge-podge' regulation of alternative medicine in Canada
}

Published at www.cmaj.ca on July 29

$\mathrm{A}$ s Ontario drafts standards of practice for homeopathy and traditional Chinese medicine, the debate continues across Canada over whether or not it's necessary to regulate complementary and alternative medicine.

Province-appointed transitional councils for practitioners of homeopathy and traditional Chinese medicine are in the midst of establishing professional colleges, entry to practice requirements, standards of practice and effective disciplinary systems. This transition phase is expected to wrap up by 2012 , at which time draft regulations will be submitted to the Ontario government for approval.

Right now, both homeopathy and traditional Chinese medicine remain almost entirely unregulated in Canada, as are most complementary and alternative medicine (CAM) practices.

"It's a hodge-podge patchwork, which can be confusing for the consumer at the best of times," says Heather Boon, founding chair and principal investigator of the Canadian Interdisciplinary Network for CAM Research.

Ontario will be the only province to regulate homeopathy, the practice of stimulating a patient's natural healing processes by administering minute doses of drugs thought to produce the same symptoms as the patient's disease, also known as treating "like with like." Practitioners of traditional Chinese medicine, who treat disease by restoring the flow of energy through the body with herbal remedies and therapies like acupuncture, were first regulated in British Columbia.

With regard to Canada's other CAM practitioners, only chiropractors are regulated across the country. While BC has the most stringent educational standards for massage therapy in North America - requiring three years of

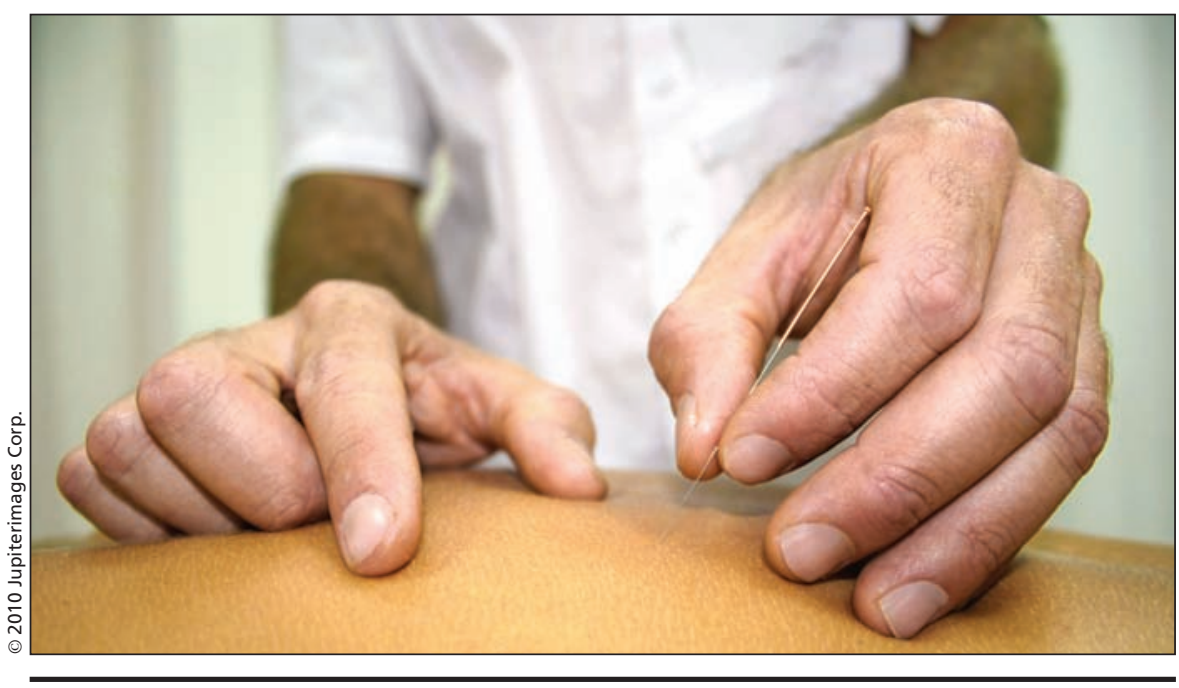

How capable are these hands? Patchy regulation of complementary and alternative medicine in Canada makes it tricky for patients to parse the qualified from the quacks.

training for entry to practice - the profession is regulated in only two other provinces: Ontario and Newfoundland and Labrador. Acupuncturists are regulated in BC, Alberta and Quebec. The practice will also fall under Ontario's new regulations for traditional Chinese medicine. Naturopathic medicine, a system of therapeutics that emphasizes the body's ability to heal itself, is regulated in BC, Saskatchewan, Manitoba, Ontario and Nova Scotia. Alberta expects to introduce regulations in 2011.

Some CAM practices, like homeopathy, were once regulated under the provincial colleges of physicians and surgeons, but were dropped from the colleges' regulatory purview in the mid-20th century.

"There's been a resurgence of interest in complementary medicine since the 1990s, but with that interest there's also been growing concern about the quality of care these practitioners provide," says Boon.

Despite the relative safety of the therapies they employ, CAM practitioners can still cause harm to their patients and therefore need regulations, says Janet Blanchard, policy and communications officer for the Transitional Council of the College of Homeopaths of Ontario. "Unregulated practitioners may make inappropriate claims, or they may fail to refer a patient to a colleague or another profession, which can certainly cause harm. There's also the issue of sexual impropriety, which is something all health professions have to be aware of and have mechanisms for dealing with."

Without regulation, anyone can put up their shingle as a CAM practitioner, says Boon. "Some naturopaths, for example, might have trained at an accredited college or school, some might have taken a weekend course, and others may have no training at all. They can all call themselves naturopaths, unless the term is protected by regulation."

Those patients who receive bad advice or care from unregulated and potentially untrained practitioners have no legal or institutional recourse, says Mirsada Vins, head of the homeopathy department at the Toronto-based Ontario College of Homeopathic Medicine. "There've been individuals in the 
past who've tried contacting different associations for help, but without regulatory powers from the province, there's nothing those groups can do. They're just volunteers."

Where there aren't any regulations in place, a patient "may as well complain they've received bad advice or care from a neighbour," adds Boon. "When a profession is regulated their college will have quality assurance programs and disciplinary committees set up to investigate complaints. But if you see someone who isn't regulated, the courts view it as poor judgment on your part, not poor practice on the part of the practitioner, unless they physically harm you. But that's pretty rare because alternative therapies are usually quite subtle and noninvasive."

For those skeptical of CAM, the "subtlety" of treatment begs the question: How can you set standards for something many people argue does not and cannot work?

"Just like setting standards for any other profession," says Basil Ziv, registrar of the transitional council. "If you look beyond the homeopathic remedy, we're looking at ethical issues. And also, I think the idea is to bring all health care professions onto a level playing field and hopefully encourage interprofessional collaboration."

The medical community, however, is less eager to see that playing field levelled, says Boon. "It's been argued that the state is attempting to take away the medical dominance which has been a part of our health care system since it was founded by allowing a larger range of health care providers to perform tasks that once were the exclusive domain of physicians."

Last year, naturopathic doctors in Ontario and BC celebrated legislative gains that will allow them to prescribe drugs as well as natural products (www.cmaj.ca/cgi/doi/10.1503/cmaj.10 9-3112).

Regulation also makes it possible for CAM practitioners to lobby for increased coverage by public and private health payers, says Boon. "The government has said, 'No way, we're not paying for your services.' But at very least, regulation is a minimum prerequisite for coverage, and private health payers are maybe more flexible."

But not all CAM practitioners are welcoming regulation. Most recently, the Canadian Society of Homeopaths has stated strong opposition to the regulation of their profession in Ontario. According to a release from the society, the province needs "many more homeopaths" than it currently has in order to adequately fund a professional college and the profession should be building unity among its members before making any attempt to impose regulations from the top down (www.csoh.ca/PA_Regulation _Ontario_Background.htm).

The number of CAM practitioners in a province often plays a role in whether or not CAM is regulated, says Boon. "The profession has to bear the cost of regulating and when you get to the smaller provinces, particularly out east, the economies of scale just don't make sense. There's been discussion about setting up a college that would regulate practitioners from more than one province, but there's no precedent for doing that. It's also possible to have colleges that regulate more than one profession."

According to a survey of more than 100 Ontario homeopaths conducted by the Canadian Society of Homeopathy, $86 \%$ were opposed to sharing a college with another profession, while $40 \%$ were opposed to the suggestion of regulation in any form.

"There's always going to be people who don't want restrictions on their practices, fees to pay, and who fear they may have to go through extra training to meet the requirements," says Vin.

Ultimately, Boon says, it's a question of where to draw the line on regulation. "There comes a point when you just have to use some common sense, and it doesn't make sense to take advice from someone who isn't held accountable and has no education. You can only regulate so much before you're protecting people from their own stupidity." - Lauren Vogel, CMAJ

DOI:10.1503/cmaj.109-3325 